\title{
The Study of ZHONGSHAN Park Green Land Structure in SHAOGUAN
}

\author{
Qi YAN, Jun LI*, Jiequan LI \\ Shao Guan University, Shao Guan City, Guang Dong Province, China
}

\begin{abstract}
In order to discuss the rationality of park green land structure, using relative importance values, biodiversity index and plant coverage, combined with SPSS analysis method, the structure of ZHONGSHAN park green space was studied based on 51 sample areas investigation of ZHONGSHAN park in SHAOGUAN city. The results showed: Ficus microcarpa and Ficus altissima were the dominant species of the tree layer. Rhododendron pulchrum, Duranta repens and Excoecaria cochinchinensis Lour were the dominant species of the shrub layer. Hymenocallis americana was the dominant species of the herb layer. The biodiversity of tree layer was the highest, the following was shrub layer, the lowest was herb layer, which displayed that there was main characteristics of tree layer in plant disposition of ZHONGSHAN park. There was positive significant relationship between plant coverage and Margalef index, Simpson index, Shannon-wiener index, Pielou evenness index and average of mentioned above biodiversity index. It was a good sign and design index to use plant coverage in the aspect of biodiversity design. From the aspects of green land structure, the park was lack of open forest grassland, forest square (turf) space and semi-open space and had no heterogeneity scene.
\end{abstract}

KEYWORDS: ZHONGSHAN park; green land structure; relative importance values; plant coverage; biodiversity

\section{INTRODUCTION}

Green space is not only a place that provides leisure recreation space for people, but also a function space that can slowdown thermal conductivity effect, greenhouse effect and create healthy environment. [1][3] SHAOGUAN city belong to subtropical humid monsoon climate, is one of the key forest areas in China, also a forestry leading market in GUANGDONG province with the advantages of having rich gen-bank. The city pattern of linking common mountains and rivers lays a solid environmental foundation. But from the aspect of city green land construction situation, the green land construction has some problems, such as powerless ecological regulation services, simple green land structure, and so on. Therefore, taking SHAOGUAN city comprehensive park as research object, through investigating green land problems and researching green land structure, the basis data are provided to build new parks, thereupon come into being basis for regulating correlation between environment and human, which ensure to build safe, high efficiency, environmental protection and comfortable green land.[2]

\section{RESEARCH AREA SITUATIONS}

The ZHOANGSHAN park in SHAOGUAN city locates in the intersection of the 3 rivers, about $12 \mathrm{ha}$ in total area, which was one of the earliest comprehensive parks intended to build. (Fig, 1) Now, there are 81 plant species, including trees of 18 families 28 genera and 42species,shrubs of 20 families, 21 genera and 21 species, herbs of 8 families 14 genera and 16 species, lianas 1 families 1 genera and 2 species.

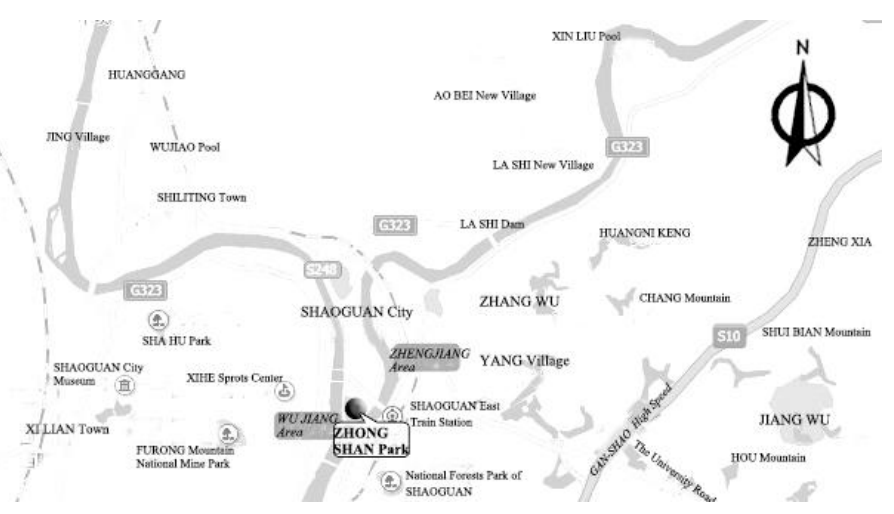

Figure 1: ZHONGSHAN park location 


\section{ANALYSIS METHODS}

\subsection{Analysis Index of Greenland Structure}

For convenient investigation and analysis, the ZHONGSHAN park was divided into 51 round samples with $10 \mathrm{~m}$ radius. The main analysis index of green land structure included plant dominance structure and plant configuration morphology.

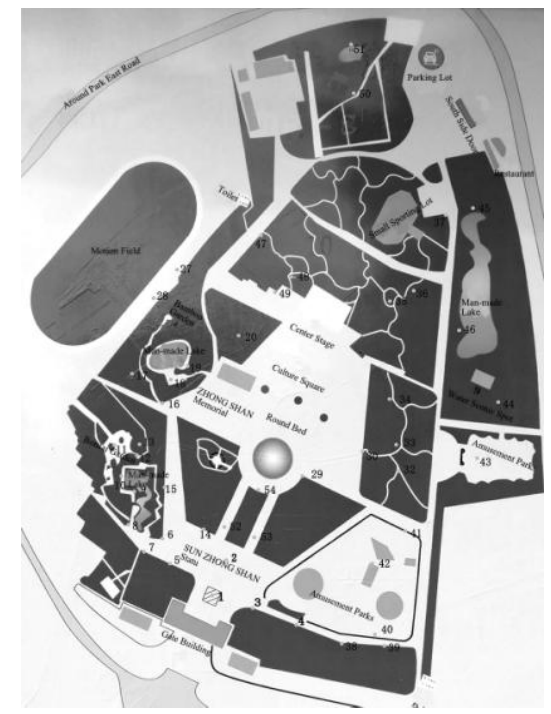

Figure 2: ZHONGSHAN park planar graph

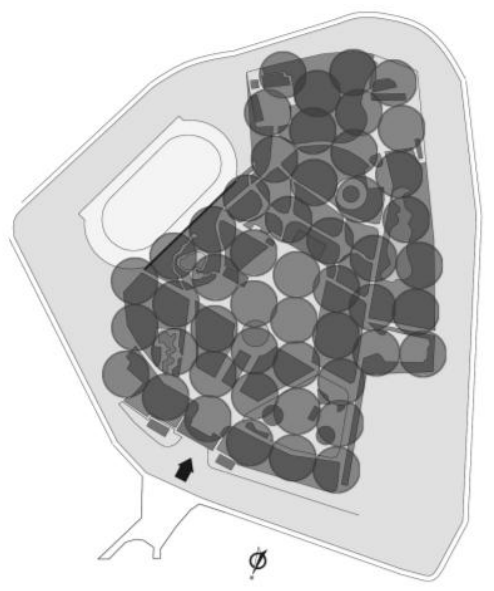

Figure 3: Samples distribution

Plant dominance structure: collecting basic information of ZHONGSHAN park plants, including species, diameter, crown width, number and so on, introducing relative importance values ${ }^{[4][5]}$, the dominance situation of park green land plant was analyzed.

Plant configuration morphology: classifying plant configuration types, introducing biodiversity [4-5], combined with plant coverage, ZHONGSHAN park plant configuration structure was studied.

\subsection{Analysis Data Source}

The data involved in analysis indicators included: plant families genera and species, relative importance values, Margalef index, Simpson index, Shannon-wiener index, Pielou evenness index, plant coverage. The involved data were arranged and analyzed by using EXCEL and SPSS program.

\section{RESULTS AND ANALYSIS}

\subsection{The Relative Importance Values Analysis of Plant}

The relative importance values of trees, shrubs and herbs in park green land were as followed:

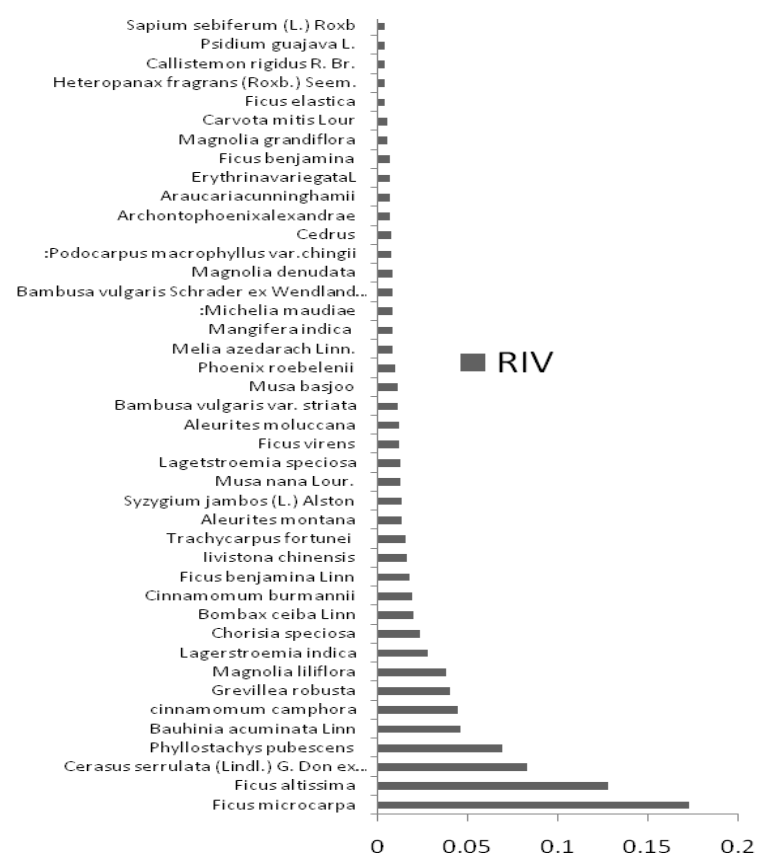

Figure 4: the relative importance values of trees layer

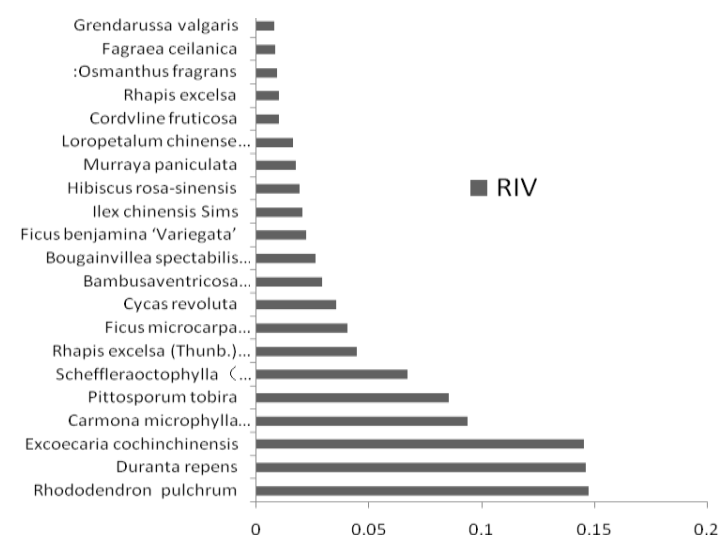

Figure 5: the relative importance values of shrubs layer

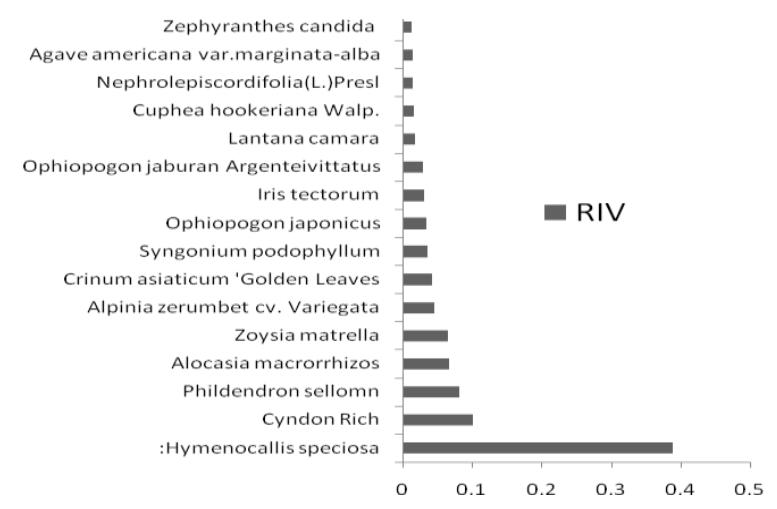

Figure 6: the relative importance values of herbs layer *RIV represents relative importance values 
From Fig.4 to Fig.6,among 42 tree species, there were only 4 species whose relative importance values were more than $0.05,9.5 \%$ of all trees, 2 among which was Ficus microcarpa and Ficus altissima with more than 0.1 relative importance values, both of two trees being Ficus (Moraceae). Meanwhile, the proportion and application range of the other tree species were limited.

Among 21 shrub species, there were 6 species whose relative importance values were more than 0.05 , half of which were more than 0.1 , they were Rhododendron pulchrum, Duranta repens and ExcoecariacochinchinensisLour. Rhododendron pulchrum is SHAOGUAN city flower, which could display region characteristic by large usage, but it was lack of changes in terms of species richness.

In the herbs layer, there were 2 whose relative importance values were more than $0.1,12.5 \%$ of all herbs. The relative importance values of Hymenocallis americana was far more than the others, showing very significant importance.

\subsection{Analysis of Plant Configuration Morphology}

There were 51 investigation samples, 46 valid. The biodiversity of tree layer, shrub layer and herb layer were analyzed by introducing biodiversity index (Margalef index (Ma), Simpson index (D), Shannonwiener index $\left(\mathrm{H}^{\prime}\right)$, Pielou evenness index $\left.(\mathrm{J})\right)$.

Table1: the biodiversity of plant in park

\begin{tabular}{|c|c|c|c|c|c|}
\hline layers & $\mathrm{Ma}$ & $(\mathrm{D})$ & $\left(\mathrm{H}^{\prime}\right)$ & $(\mathrm{J})$ & average \\
\hline trees layer & 0.265 & 0.35 & 0.633 & 0.325 & 0.39325 \\
\hline shrubs layer & 0.178 & 0.173 & 0.298 & 0.219 & 0.217 \\
\hline herbs layer & 0.064 & 0.091 & 0.144 & 0.151 & 0.1125 \\
\hline average & 0.169 & 0.205 & 0.358 & 0.232 & \\
\hline
\end{tabular}

The data in table 1 showed that the highest biodiversity was tree layer, the following one was shrub layer, the lowest one was herb layer, which expressed the design concept that the characteristic of plant configuration in ZHONGSHAN park was mainly tree layer, shrub complementary and herb simple collocation.

The types of plant configuration in park green land could be divided into 7classes, including single tree layer, single shrub layer, single herb layer, treeshrub double layer, tree -herb double layer, shrubherb double layer, trees brushes and herbs compound layer. Through investigation, in the valid green land samples, there were 5 plant configuration structures, including single tree layer(3), single shrub layer(1), tree-shrub double layer (13), tree-herb double layer(9), trees brushes and herbs compound layer(19). In order to explore biodiversity of plant landscape in samples, the relationship between samples coverage and biodiversity was analyzed as followed. (Table 2)
Table 2: The relationship test between samples coverage and various biodiversities

\begin{tabular}{|c|c|c|c|c|c|c|}
\hline \multicolumn{2}{|c|}{} & Ma & $(\mathrm{D})$ & $\left(\mathrm{H}^{\prime}\right)$ & $(\mathrm{J})$ & average \\
\hline \multirow{2}{*}{$\mathrm{C}$} & $\begin{array}{c}\text { Pearson } \\
\text { relationship }\end{array}$ & $.342^{*}$ & $.334^{*}$ & $.345^{*}$ & $.307^{*}$ & $.340^{*}$ \\
\cline { 2 - 6 } & $\begin{array}{c}\text { Significant } \\
(2-\text { tailed })\end{array}$ & .020 & .023 & .019 & .038 & .021 \\
\hline
\end{tabular}

*C represents Coverage

Seen from various index of table 2, there was positive significant correlation between coverage and various biodiversity index, that is: the larger the sample coverage was, the richer the biodiversity of plant community would be. Therefore, during the course of design, in order to enhance landscape effect, plant biodiversity could be increased by improving green land coverage, vice versa, biodiversity degree of plant community could be learned by investigating plant plots coverage.

By investigation, in five types of ZHONGSHAN park green land configuration, the coverage of trees brushes and herbs compound layer was the highest, corresponding high biodiversity, and that of single shrub layer was the lowest, corresponded the lowest biodiversity. The trees brushes and herbs compound layer was main configuration structure, account for $42.2 \%$, highest in the whole park, which could reflect plant diversity characteristic. Meanwhile, there were lack of 2 types configuration-single herbs layer and shrub and herb double layer-and not much single tree layer and single shrub layer, which caused green land space lack of variation.

\section{CONCLUSIONS AND SUGGESTIONS}

\subsection{Conclusions}

Firstly, Introducing relative importance values, the dominant species of trees, shrubs and herbs in park were analyzed, the conclusions were as followed: Ficus microcarpa (relative importance values 0.172918599) and Ficus altissima (relative importance values 0.128609786 ) were the dominant species of the tree layer. Rhododendron pulchrum (relative importance values 0.147103), Duranta repens (relative importance values 0.146042) and Excoecaria cochinchinensis Lour (relative importance values 0.145306) were the dominant species of the shrub layer. Hymenocallis Americana (relative importance values 0.389281) were the dominant species of the herb layer. The application of these plant mentioned above occupied main position, which made the landscape of function regions in ZHONG SHAN park show a unified common, whereas, the application of the other plants was very thin-such as SHAOGUAN city tree Cinnamomum burmannii (relative importance 
values 0.019328685$)$. There was no heterogeneity scene in the whole park.

Secondly, It was known by analysis of trees brushes and herbs compound layer in park that the diversity of tree layer was the highest, that of shrub layer was middle, and that of herb layer was the lowest. It came to the conclusions by relationship analysis between coverage and biodiversity in 46 valid plant samples of ZHONGSHAN park: there was positive significant relationship between sample coverage and biodiversity, that is: the larger the samples were, the more obvious characteristic the samples biodiversity would be.

Thirdly, Combined with research aiming to relative important values and biodiversity of park, it was known that plant configuration of ZHONGSHAN park was main trees brushes and herbs compound layer (42.2\%), which was beneficial to display diversity characteristic, but because of limitation of plant species application, there only formed simple plant community landscape with weak heterogeneity. The plant configuration structures in ZHONGSHAN park were lack of single herb structure and shrub-herb double structure, less application in single tree structure $(6.5 \%)$ and single shrub structure (2.2\%). From the perspective of park landscape expression forms, there were lack of open forest grassland, forest square (turf) space and semiopen space.

\subsection{Suggestions}

ZHONGSHAN park is most important comprehensive park in SHAOGUAN city, also one of the important measure standard of city green land construction, therefore, some suggestions should be proposed:

Firstly, Enhance richness of plant species in park. SHAOGUAN city has good congenital basis. Firstly, different seasonal aspect, color, morphology of native tree species should be boldly used to increase plant landscape heterogeneity, which will increase landscape effect in park green land. Secondly, it is a effective way to enlarge SHAOGUAN city tree relative important values to enhance region characteristic of park green land.

Secondly, Improve plant configuration structure, create open and shut green land space morphology. Based on keeping trees-shrubs-herbs compound dominance structure, the absent structure morphology-single herbs structure and shrubs-herbs double structure- should be made up, that is: increase the mall space and surrounding space green land structure. Meanwhile, increase number of single tree structure, that is: increase open grassland forest space. The spatial changes from open space to semiopen space to semi-enclosed space to enclosed space will come into being by improving plant configuration.

\section{ACKNOWLEDGEMENTS}

Research Project of SHAOGUAN University (code: 314-140645). Technical Plan Project of SHAOGUAN Bureau (code: 2014CX/K262). 2014 Annual "Teaching Quality Project" Construction of GUANGDONG---SHAOGUAN University Gardening Specialty Excellent Teaching Team.(code: 5137).

\section{REFERENCES}

[1] Shu Jun, Bai, 2003, Several Thoughts about Effect of Urban Green Land System in China, Journal of $\mathrm{Hu}$ Bei University, 88-92.

[2] Yi, Deng, 2003, The Discussion of the Development and the Concept of Urban Ecological Park. Chinese Landscape Architecture (12):51-54.

[3] Bao Zhong, Wang \& Cai Xia, Wang, 2004, The Review of Urban Green Land Research, Urban Planning Forum, (2): 61-66.

[4] Feng, Zhang \& Tie Liang, Shang Guan, 1998, The Diversity Analysis of the MIAN Mountain Forest Plants in Shan Xi, Chinese Journal of Plant Ecology, 22(5):461-465.

[5] Nan Zhang,2008, The Investigation and Research of Urban Plant Diversity in Yu Zhou City, Journal of AnHui Agri. Sci. , 36(8):3287-3288.3293. 